\title{
Author Correction: Molecular mechanisms underlying nucleotide repeat expansion disorders
}

\author{
Indranil Malik, Chase P. Kelley (1), Eric T. Wang (1) and Peter K. Todd
}

Correction to: Nature Reviews Molecular Cell Biology https://doi.org/10.1038/s41580-021-00382-6, published online 17 June 2021.

Three changes have been made to original article: disease names were added at the beginning of the Abstract; in the legend of Figure $4 \mathrm{~b}$, the words 'and initiation factors' were added to the sentence, “... other IRES trans-acting factors (ITAFs) [and initiation factors], such as elF3 and elF5"; and the citation 'FIG. $3 \mathrm{f}$ ' was changed to 'FIG. 3e'. These changes have been made in the HTML and PDF versions of the article.

https://doi.org/10.1038/s41580-021-00396-0 I Published online 6 July 2021

(c) Springer Nature Limited 2021 